\title{
SIMULATED TESTING AND ITS ROLE IN CONSTRUCTION OF AGRICULTURAL EQUIPMENT
}

\author{
Lucretia Popa, Vasilica Stefan, Ana Zaica, Alexandru Zaica, Ana-Maria Marin, Ciprian Miron \\ National Institute of Research-Development for Machines and Installations \\ Designed to Agriculture and Food Industry, Romania \\ lucretia_popa@yahoo.com,valle_vali@yahoo.com,zaica_ana@yahoo.com, \\ zaica_alexandru@yahoo.com, marin.anamaria26@gmail.com,m.ciprian24@yahoo.com
}

\begin{abstract}
In the process of agricultural production, a large percentage is represented by transport works. The transport of agricultural products and materials is carried out in a proportion of $70 \ldots 80 \%$ on public roads, which means that all means of transport that travel on these roads must be designed and equipped in strict accordance with the regulations in force on road safety. This article presents the results of the research conducted for the construction of a two-part tipper trailer, equipped with two axles, designed in cooperation with a Romanian company. The activities carried out fell into the category of applied research. Three-dimensional design can ensure precision in execution, shortening the time to supply a product on the market, reducing the time required for the entire flow, from design to manufacturing, testing and mass production. In order to accelerate the research and shorten the period until the realization of the experimental model, in the design phase simulated research was performed, using the SolidWorks Simulation module. These researches contributed to the correct choice of materials, as well as to the precise determination of the dimensional characteristics of the various subassemblies. The main subassembly studied by virtual testing was the axle of the trailer. A good dimensioning of the trailer components ensures the safety in operation and contributes to the optimization of the trailer production process, eliminating the irrational consumption of raw materials. The integration of the subassemblies tested by simulation, and later by experimental research in real working conditions, led to the performing of an agricultural trailer with a payload of 7 tons, contributing to the development of the agricultural machinery construction in Romania. The article presents the results of the static analysis of the trailer axle of the rolling system, using virtual testing to look for vulnerabilities, as a necessary stage of the development process.
\end{abstract}

Keywords: three-dimensional design, agricultural transport.

\section{Introduction}

The design and construction of tractor trailers implement research results for car trailers, especially when talking about a single axle trailer. Much of the known research on the construction of tractor trailers has as its subject the steering system that allows the change of direction of travel [1]. Michalek presents a trailer-manoeuvrability analysis for the $\mathrm{N}$-trailer kinematic structures comprising a tractor and an arbitrary number of single-axle trailers equipped with steerable or fixed wheels. The article provides some relations between kinematic parameters of the $\mathrm{N}$-trailer and its control inputs, which enable shaping the trailer-mobility ellipse and decoupling it from a joint-configuration of the vehicle.

The vertical tyre force is crucial to the study of the dynamics of a tractor semi-trailer. Tung, Huong and Kiet present in their paper [2] an experimental method for determining the vertical tyre force by determining the vertical acceleration of the un-sprung mass and the vertical acceleration of the sprung mass when the tractor semi-trailer moves. The results of this study form the basis for determining the dynamic tyre force without installing of sensors on road [2].

Traditional articulated vehicles have poor steering performance because there is no direct rotation moment for the undersized trailers, which makes such vehicles almost not work well in tight space. Some authors have done advanced research on improving the steering system of the articulated tractortrailer unit [3]. Another article, written by Abroshan et al., presents the research performed for improving the manoeuvrability of an articulated aggregate tractor-trailer [4]. A controller for an automated steering articulated vehicle with the special capability to reduce off-tracking in low-speed manoeuvres is proposed. Conventional tractor-trailers have a large off-tracking in low-speed manoeuvres. In the proposed vehicle all wheels of the tractor and trailer are steerable (all wheel steering). The controllers of the tractor and trailer work independently, and each one consists of two layers. A fuzzy controller and a PID controller are designed in the upper and lower layer, respectively, to control the actuators. The aim of the controller is to ensure that the end points of both the tractor and the trailer exactly follow the path of the tractor's first point. The simulation results confirm that the proposed approach improves the manoeuvrability and accuracy of path tracking not only compared to conventional vehicles, but also 
to the conventional tractor-active trailer scheme. Additionally, it reduces lateral tire forces to enhance the working life.

The directional instability problem of a truck and trailer combination in a forward motion has been investigated by developing a dynamic model of the planar rigid-body dynamics of the system. Two control strategies have been devised based on the reference model following controller configuration. The main objective of the controllers is to ensure that the nonlinear model follows the desired response generated by a linearized version of the truck and trailer model. The first RFMC uses an integral-plusstate feedback controller for its compensator, which was designed based on the eigen structure assignment methodology. The second RFMC relies on a sliding mode compensator. The control inputs were applied through the actuation of differential wheel torques. Different driving scenarios and road conditions, such as braking and accelerating manoeuvre with a flat tire on a dry road, and a double-lane change manoeuvre on a slippery road, were considered. Overall, the simulation results demonstrated the superiority of the sliding mode controller over the integral-plus-state feedback controller in ensuring better tracking of the truck and trailer combination to a target path under different driving manoeuvres [5].

The manoeuvrability of vehicle combinations is important because vehicle combinations are an important part of road traffic. It is necessary to examine the manoeuvrability of vehicle combinations because of crossing intersections and roundabouts. Good manoeuvrability can contribute to better safety on the roads. In the paper written by Jagelcak at al. there are described European legislative conditions for vehicle and vehicle combination manoeuvrability. The aim of this paper was to compare the results of measurements in the circles of manoeuvrability of selected semi-trailer vehicle combinations and to investigate the impact of a liftable axle of a semi-trailer. The results of measurements were compared with software simulation where is simulated crossing of the semi-trailer in the circles of manoeuvrability [6]. Many other authors have done research regarding some methods for improving the steering system $[7 ; 8]$.

In the literature, researchers studying the lateral dynamics of tractor-trailer systems have each developed their own reduced-order lateral dynamic model, each with their own assumptions, state representations, and derivation methods. Little to no work has been performed to compare the accuracy of these models to each other, nor to validate their results against high-fidelity multi-body simulations or real truck data.

The purpose of the research done by some authors was to identify several reduced-order lateral dynamic models for tractor-trailer systems present in the current literature, simulate their estimated states through common driving manoeuvres, and then compare their estimates against reference data from a high-fidelity multi-body dynamic model. From this comparison, they identified the reduced-order model that maintains the least error from the reference data as the best representation of a real tractortrailer system. The results of their comparison can be useful to researchers interested in using a reducedorder dynamic model from the literature as the basis for articulation angle estimation, model-predictive control, or adaptive control algorithms for autonomous tractor-semitrailer systems [9].

There are also known researches regarding the braking system or self-steering, or for other parts of the trailers, for improving the construction of the trailer or semitrailer [10-13].

This paper presents the results of an applied type research, which was performed for design and construction of a double axles trailer, for transport of the agricultural products, bulk or packaged, in order to implement in series production of a trailer with a payload of 7 tons.

\section{Materials and methods}

The trailer design was performed using 3D design software, 3D SOLIDWORKS, which offers the possibility of a simulated test of certain main subassemblies, important parts of the trailer, using hardware that are part of the Research Infrastructure for Technical Systems from Agriculture, Forestry and Food Industry (https://eeris.eu/ERIF-2000-000L-0243).

The virtual testing accelerated the product development, which provided the possibility to integrate into production of the trailer in a short time. The simulation of the behaviour of the trailer axle, using the SolidWorks Simulation software, has been performed.

The virtual analysis had several stages: 
- performing fixtures;

- applying of forces or pressures;

- choosing of material;

- virtual testing;

- viewing results;

- optimization of the constructive solution, if necessary.

The axis (Figure 1) has been designed taking into account the preliminary calculation of the shear force diagram and also the bending moment. Before virtual testing, the axle was designed simplifying the construction, the finite element mesh, fixtures and loading forces were established. Based on the chosen discretization variant (solid meshing), the static study was performed, according to the calculation scheme established by the initial data of the overall design of the trailer.

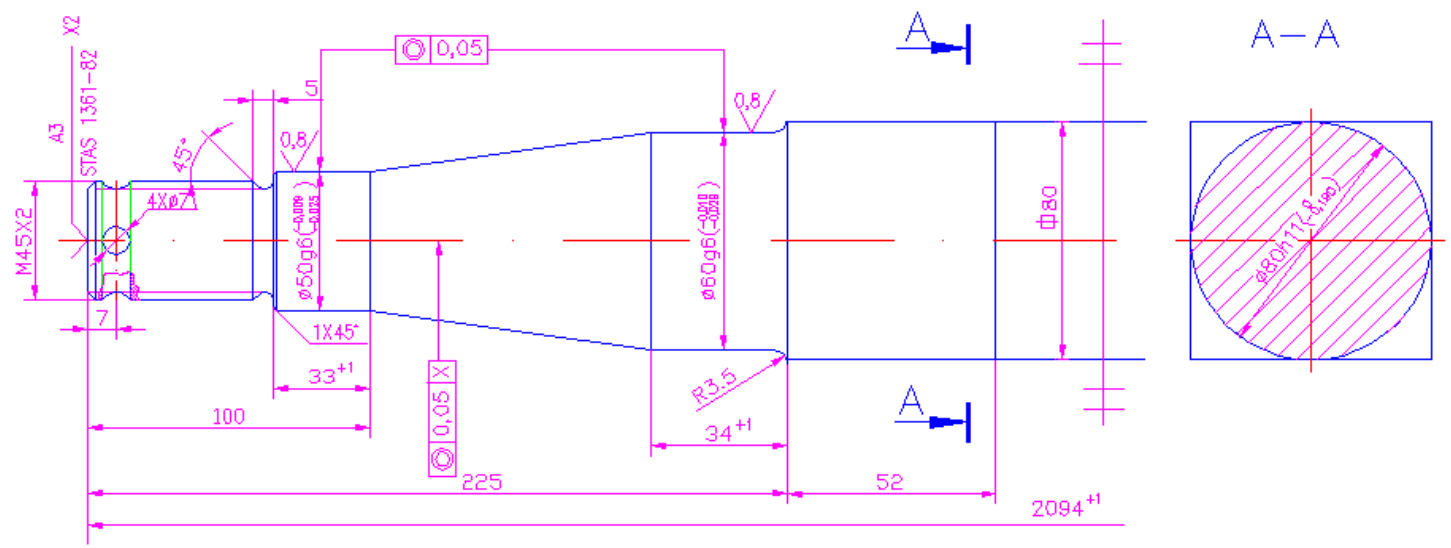

Fig. 1. Axle design

\section{Performing constraints}

The purpose of establishing the constraints is to identify the immobilization areas of support type, bearing, embedding, etc., depending on the way in which it is desired to cancel the movements. In the case of the axle, the fixtures were of the bearing type, even in the spindle areas where the bearings are mounted on the axle (Figure 2).

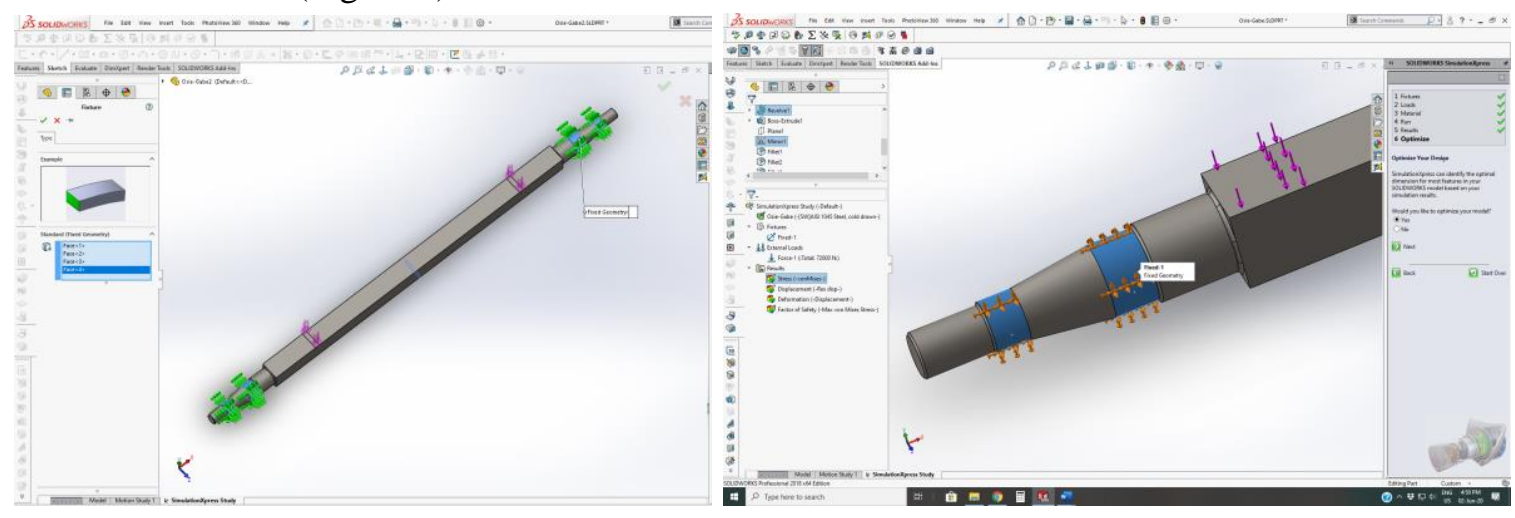

Fig. 2. Constraints defining

\section{Applying of forces}

Taking into account the maximum mass of the trailer, which is of $10.000 \mathrm{~kg}$, an overloaded mass by $30 \%$ was added. So, a force of $65 \mathrm{kN}$ was distributed on the axle. The force on the axle was considered to be concentrated in the area where the leaf springs have been placed, at a distance of $1060 \mathrm{~mm}$, on the transversal direction (Figure 3). For these values, the virtual analysis of the axle behaviour at static conditions was performed. 


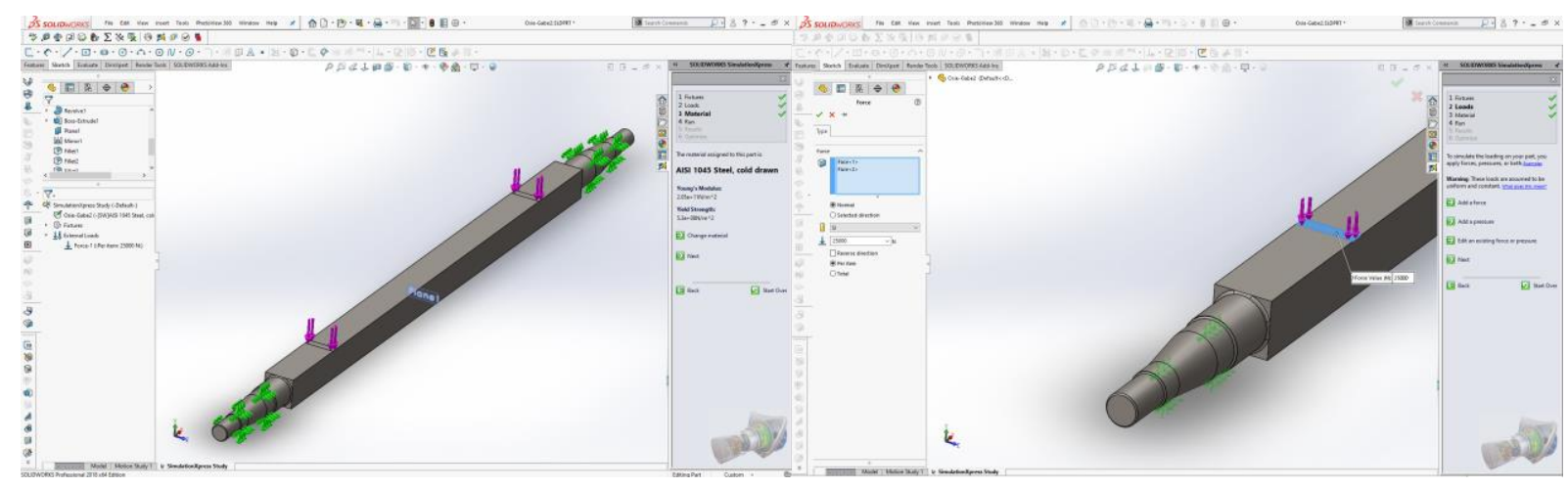

Fig. 3. Forces applying on the leaf spring area

Choosing of material

Carbon steel AISI 1045, with the following characteristics was chosen (Table 1).

Properties of Carbon Steel AISI 1045

Table 1

\begin{tabular}{|l|c|c|}
\hline \multicolumn{1}{|c|}{ Mechanical property } & Value & Measure unit \\
\hline Elastic Modulus & $2.05 \mathrm{e}+05$ & $\mathrm{MPa}$ \\
\hline Poisson's Ratio & 0.29 & - \\
\hline Shear Modulus & $8 \mathrm{e}+04$ & $\mathrm{MPa}$ \\
\hline Mass Density & 7850 & $\mathrm{~kg} \cdot \mathrm{m}^{-3}$ \\
\hline Tensile Strength & 625 & $\mathrm{MPa}$ \\
\hline Yield Strength & 530 & $\mathrm{MPa}$ \\
\hline
\end{tabular}

Before running the program, it was verified that the axle is firmly attached, aiming animation behaviour request to check the correct application of forces.

Meshing

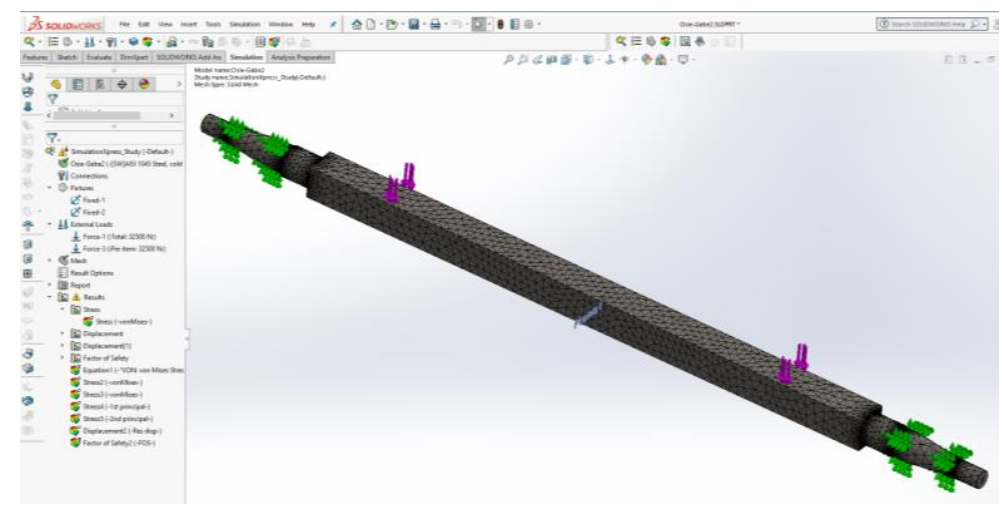

Fig. 4. Finite element mesh

Meshing applied in analysis has the characteristics below.

- Mesher Used: Standard mesh.

- Jacobian points: 4 points.

- Element size: $22.4944 \mathrm{~mm}$.

- Tolerance: $1.12472 \mathrm{~mm}$.

- Mesh quality: High.

- Total nodes: 16765 .

- Total elements: 10135.

- Maximum Aspect Ratio: 12.686.

- Percentage of elements with Aspect Ratio < 3: 94.1.

- Percentage of elements with Aspect Ratio > 10: 0.286. 


\section{Results and discussions}

For the axle part model of the trailer equipped with a rolling system by double axles, analyzed in this study, the results obtained from the simulation in Solid Works are presented below.

Virtual testing and results

The program has been run for performing the simulation and the information for the static behaviour of the axle was obtained at the following.

- Stress (von Mises). Von Mises stress criterion was used to verify if the axle will yield or fracture under the forces applied (Figure 5).

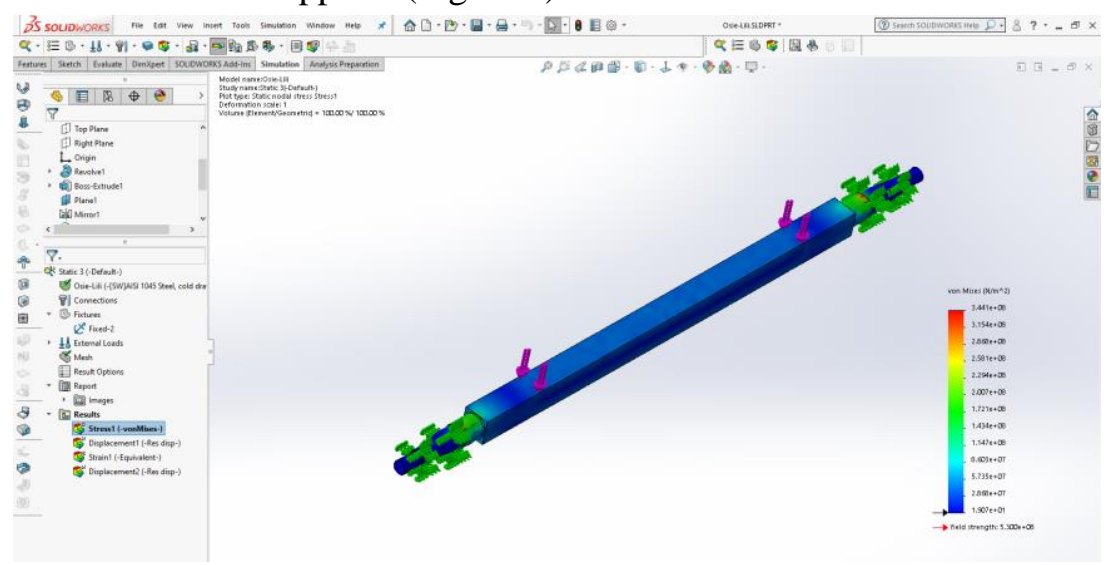

Fig. 5. Von Mises stress distribution

The maximum yield strength for the material is of $530 \mathrm{MPa}$. Making an ISO clipping, the area can be seen affected by the maximum stress $539 \mathrm{MPa}$ and what is the percent of the part, which has been affected by the maximum yield strength (Figure $6 a$ ).

As we can see in Figure 6a, the volume affected by the maximum stress is almost zero. An area can be seen for the maximum stress, but this is a local area, which does not affect the resistance of the axle and can be ignored (Figure 6b). Ignoring this punctual area affected by the maximum value of stress, it can be observed that the maximum stress is around $110 \mathrm{MPa}$.

If we were not satisfied, we could improve the construction and make another simulation. But the results have given us the confidence that the behaviour of the axle subjected to stress satisfies the working requirements.

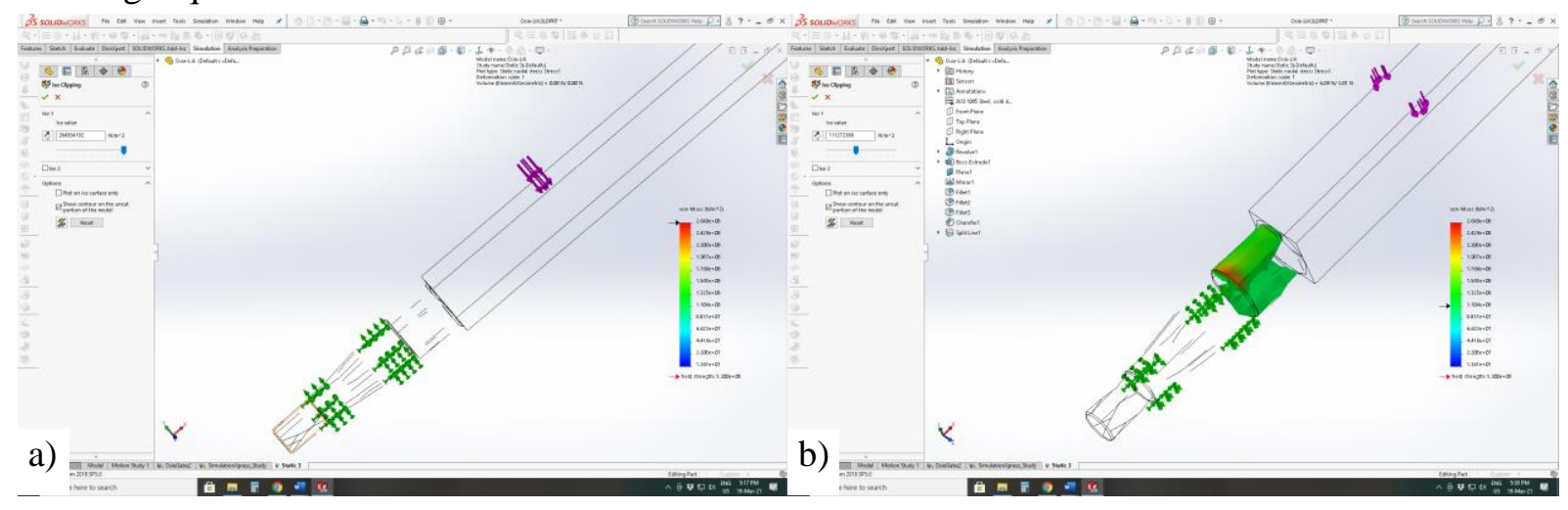

Fig. 6. Iso Clipping stress behaviour

- Displacement. Under the forces applied, we can see that the deformation is insignificant, the maximum value is $1.725 \mathrm{~mm}$, which means the axle has been well designed and there are no problems for the static load. 


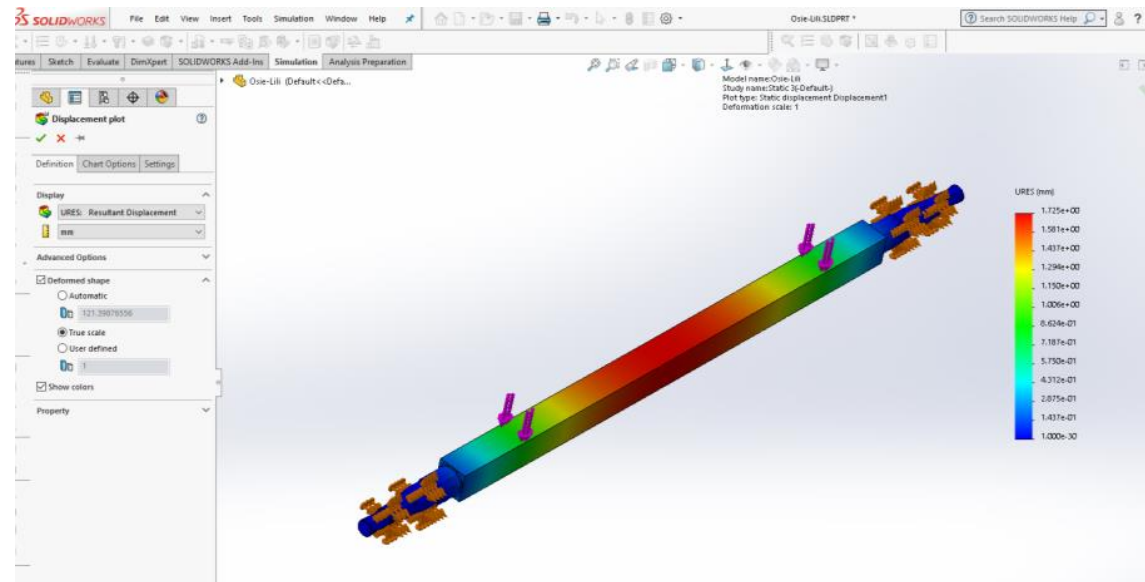

Fig. 7. Displacement

- Factor of Safety (FoS): We imposed from the initial conditions a safety factor FoS $=4$. Virtual simulation gave us the result, as we can see in Figure 8. Almost $100 \%$ of the part has a safety factor at a high value. Making an ISO Clipping, as in Figure 9, it can be seen that only a punctual surface has been affected and has $\mathrm{FoS}=0.9$.

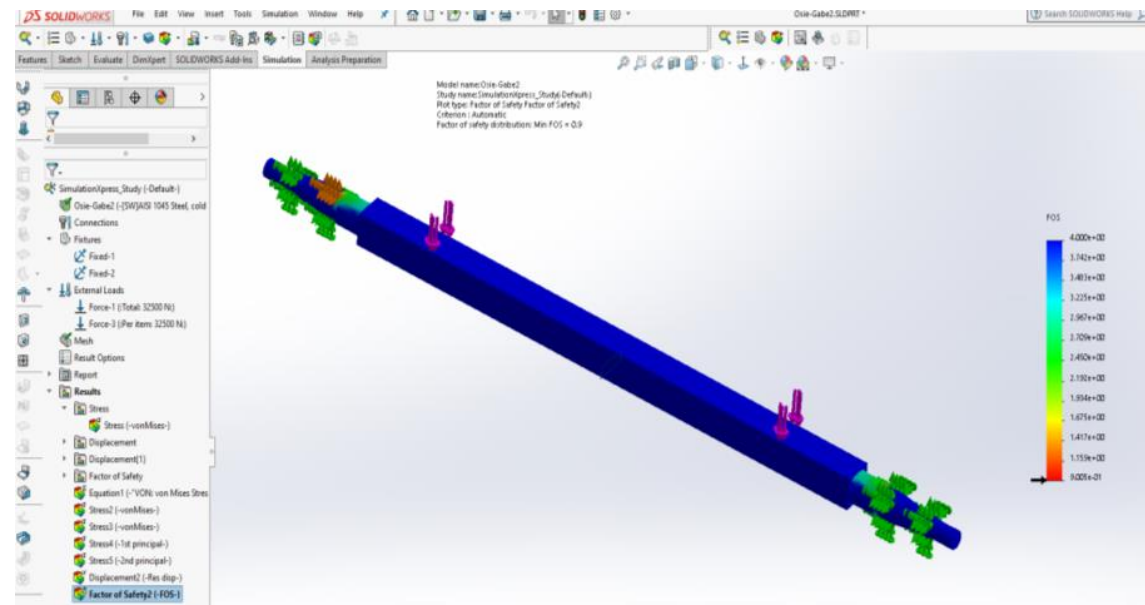

Fig. 8. Factor of safety graph

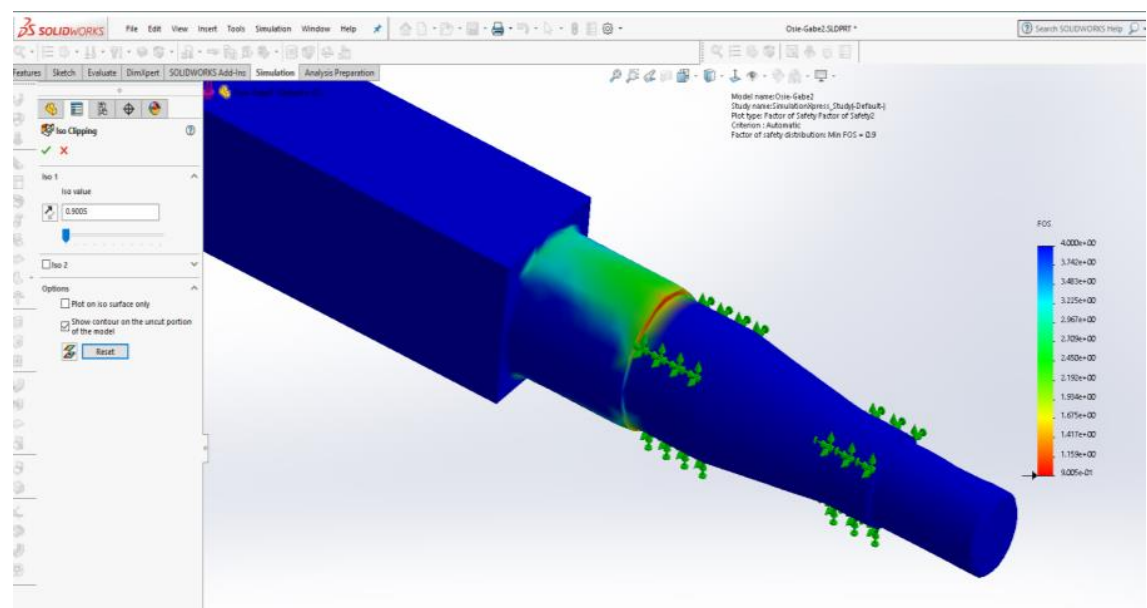

Fig. 9. ISO Clipping for analysing the safety factor

The experimental model of the trailer, symbol RB-7, with a payload of $7000 \mathrm{~kg}$ was equipped with the axles studied (see Figure 10). It is a trailer equipped by a rolling system with two axles, the steering 
system being with periodic bearing. The trailer has been designed to transport agricultural products, and the discharge is done on two sides (left or right).

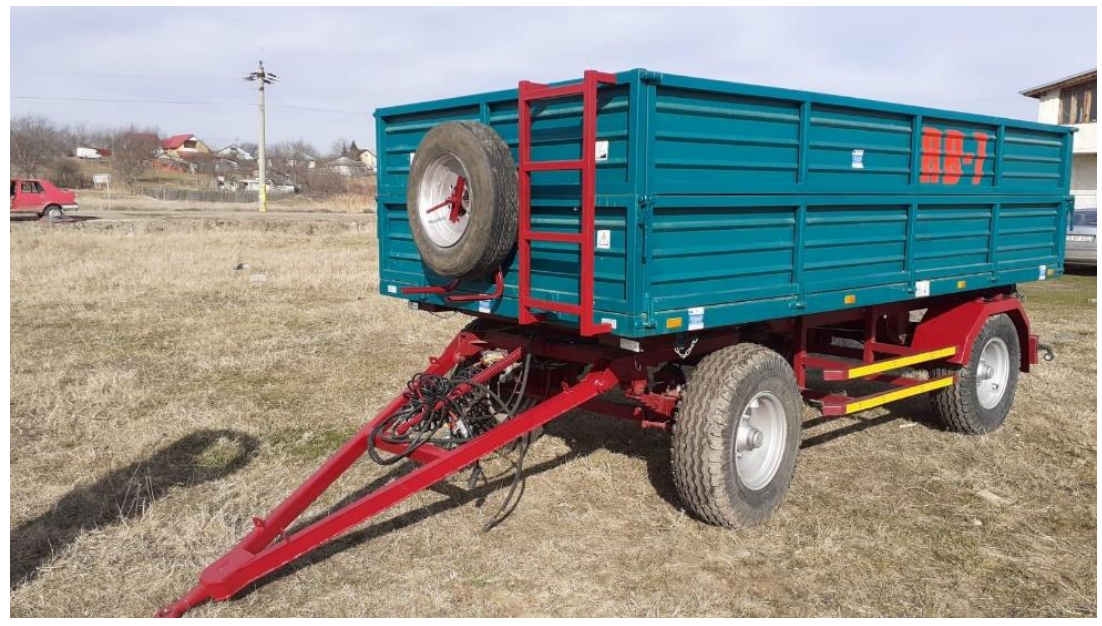

Fig. 10. Trailer RB7

\section{Conclusions}

The results of virtual experiments in static conditions have given us information about the resistance in stationary conditions. The average value of the safety factor is 2.45 . For trailers intended for the transport of agricultural products, the safety factor takes values between 1.8 and 2 . Thus, it can be said that the designed axle is adequate, taking into account the fact that from the beginning we overloaded the structure by $30 \%$. It can be concluded that the axis can withstand extreme conditions (overloading with heavier materials than agricultural products, such as sand or soil), this stress is insignificant and does not affect the structure. The research presented in this article may be useful to designers and manufacturers in the construction of transport trailers.

\section{References}

[1] Michalek MM. Trailer-Maneuverability in N-Trailer Structures. IEEE Robotics and Automotive Letters. Vol.5, Issue 4, 2020, pp. 5105-5112.

[2] Tung NT., Huong VV., Kiet PT. Experimental research on determining the vertical tyre force of a tractor semi-trailer. International Journal of Modern Physics B, Vol.34 Issue: 22-24, 2020.

[3] Liu Z.Y., Yue M., Guo L., Zhang Y.S., Trajectory planning and robust tracking control for a class of active articulated tractor-trailer vehicle with on-axle structure. European Journal of Control. Vol. 54, 2020, pp. 87-98.

[4] Abroshan M., Taiebat M., Goodarzi A., Khajepour A. Automatic steering control in tractor semitrailer vehicles for low-speed maneuverability enhancement. Proceedings of the institution of mechanical engineers. Part K-journal of multi-body dynamics. Vol. 231, Issue 1, 2017, pp. 83-102.

[5] Latif, A., Chalhoub, N., Pilipchuk, V., Control of the nonlinear dynamics of a truck and trailer combination. Nonlinear Dynamics. Vol. 99, Issue 4, 2020, pp. 2505-2526.

[6] Jagelcak J., Kiktova M., Francak M. The Analysis of Maneuverability of Semi-trailer Vehicle Combination. LOGI 2019 - Horizons of Autonomous Mobility in Europe. Book Series: Transportation Research Procedia. Vol.44, 2020, pp. 176-181.

[7] Odhams A.M.C., Roebuck R.L., Jujnovich B.A., Cebon D. Active steering of a tractor-semi-trailer. Proceedings of the institution of mechanical enginers; Part D-Journal of automobile engineering. Vol. 225, Issue D7, 2011, pp. 847-869.

[8] Sampaio R., Trigo F.C. Modelling and Simulation of the Rolling Dynamics of a Tractor-Trailer Truck Vehicle. Proceedings of DINAME, 2017. Book Series: Lecture Notes in Mechanical Engineering, 2019, pp. 417-430.

[9] Brock Z., Nelson J., Hatton R.L. A Comparison of Lateral Dynamic Models for Tractor-Trailer Systems. 2019 30TH IEEE INTELLIGENT VEHICLES SYMPOSIUM (IV19). IEEE. Book Series: IEEE Intelligent Vehicles Symposium, 2019, pp. 2052-2059. 
[10] Ciuperca R., Popa L., Nedelcu A., Borisov B., Atanasov At. Braking of trailer endowed with inertial braking system, working in aggregate with tractor. INMATEH Agricultural Engineering, vol.32, no.3, 2010, pp. 51-58.

[11]Ciupercă R., Popa L., Nedelcu A., Voicu E. Oscillations of self-steering wheels of agricultural semitrailers. Conference: Aktualni Zadaci Mehanizacije Poljoprivrede. Zbornik radova, 39. Međunarodnog Simpozija iz Područja Mehanizacije Poljoprivrede, Opatija, Hrvatska, 22-25 veljače 2011, 2011, pp. 73-81.

[12] Popa L., Moise S.I., Stefan V., Ungureanu L.M., Dudici L., Structural and kinematic analysis of lifting and folding mechanism of mobile shutter. 18th International Scientific Conference of Engineering for Engineering for Rural Development Proceedings-ERDev. Book series. Art.N406, Vol.18, 2019, pp. 655-661.

[13] Popa L., Moise S.I., Moise V., Stefan V., Tabara I., Structural and kinematic analysis of a shutter from monocoque trailer. E3S Web of Conferences. Vol.112. pp.03021. Editor: EDP Sciences 